\title{
ABOUT SOME FEATURES OF AHP/ANP APPLICATIONS
}

\author{
Olga Andreichicova* \\ Central Economic Mathematical Institute \\ Moscow Institute of Physics and Techology \\ Moscow, Russia \\ E-mail: olga.andreich@gmail.com \\ Alexander Andreichicov \\ Moscow University of Railway Engineering \\ Moscow, Russia \\ E-mail: andreichickov@mail.ru
}

\begin{abstract}
The paper describes the diversity of problem statements and solving procedures in AHP/ANP applications. AHP/ANP is considered as a powerful researching tool, which can be applied to different problems. The approach for the revealing of the most influential elements in network model is offered and demonstrated by the example. The procedure of step-by-step complication of the network model is illustrated by the example of researching the efficiency of expense items of state budget in Russian Federation.
\end{abstract}

Keywords: AHP/ANP application, problem statement, influence, priority, budgetary funds

\section{Introduction}

The evolution of AHP/ANP methodology occurs in different ways; the most important of them are the substantiation of its fundamentals, the comparing and combining with other decision-making methods, the exploring of its opportunities by examples of applications. The last item is the most diverse and complex, so as applications have the specificity that takes main attention, therefore a careful analysis of AHP/ANP applications is the urgent and interesting problem. Here it is interesting not so much the problems, which were solved with use of AHP/ANP, as the procedure of problems solving. We do not claim to do exhaustive analysis of AHP/ANP applications in this paper, but we would like to notice some features in problem statements, results' interpretations and difficulties, which can arise.

\section{Brief review of AHP/ANP applications}

AHP is the analytical tool for decision-making problems, which should be represented by the hierarchy, containing the set of alternatives at the bottom level, the main goal at the top and a number of the sets of criteria, subcriteria, factors, actors, etc. at the intermediate levels (Saaty, 1980; Saaty, 1994). The AHP applications, as a rule, have traditional statement of the problems - choose the best variant from the given set of alternatives in terms of goal, taking into consideration a structured set of criteria, factors and actors (Saaty, 1994; Saaty, Vargas, 1994; Saaty, 1999; Proceedings of ISAHP 2001, 2003, 2007, 2009, 2011). The particular class of applications are decision-making problems with use BOCR-analysis (Benefits, Opportunities, Costs, Risks), which contain a set (usually four) of hierarchies and include a procedure of

\footnotetext{
${ }^{*}$ Corresponding author
} 
the synthesis of global priorities (Saaty, 2005). It's amazing that a number of applications of marginal analysis (Saaty, 1980) is negligible, while it can give valuable results (Andreichicov, Andreichicova, 2003). Unfortunately, up today there is not available software for AHP with dynamic judgments, which is a powerful tool for forecasting. Because of this, applications of this technique are scarce (Andreichicov, Andreichicova, 1999).

Important advantages of AHP are good understandability and interpretability of the results. These advantages sometimes create impression of seeming simplicity that lead to mistakes, which, as a rule, arise from imperfect representation of the problem and from the invalid choice of measurement method for each criterion.

ANP gives the opportunity to take into consideration mutual influences of criteria and alternatives; therefore it enables to diversify problems' statements (Saaty, Ozdemir, 2005; Saaty, Cillo, 2008). Besides decision-making problems with dependence we can state the problems of researching of influence and/or forecasting of possible consequences of such influences. ANP gives the opportunity to find out the elements, which accumulate influences, and to interpret their limit priorities as impact of main goal (Saaty, 2001). Further we describe the features of ANP applications for researching of influences in difficult practical problems.

\section{ANP as a researching tool}

Analytic Network Process is a powerful tool for system analysis and qualitative simulating. One of its main advantages is that it can be applied under uncertainty, when other techniques do not work. ANP enables to describe the problem by the qualitative attributes such as clusters, nodes and relations between them. After that one can use quantitative data in the form of expert judgments for an experimental evaluating of mutual influences of the elements. Thus we have an opportunity to explore complex problem and to obtain unobvious results by the experimenting with the model thereby to achieve the better understanding of the problem. The researcher can reveal not only the elements (nodes and clusters), which accumulate influences, but also the elements, which are the most influential (Andreichicova, Radyshevskaya, 2009). In such problems a researcher should formulate his goals, but he can do without the special cluster, containing alternatives, because his interests are wider than alternatives. He has concern in the revealing of all nodes and clusters, which accumulate influence and influence other elements. Besides he can be interested in the addition and deletion of some elements and relations between them to understand the real problem better. Below we describe these research procedures by short examples.

\subsection{Revealing of the most influential elements}

When we want to research influences in a complex problem, first of all we have to build a connected network that shows these influences. We shall demonstrate the procedure by the example of researching financial crisis (Andreichicova, Andreichicov, 2009). Network model, describing this problem, is shown in the Figure 1, where one can see the cluster-source Government and the cluster-sink Macrofactors. The goal was to answer the questions "What effect will have the actions are being taken by the government (the nodes of the cluster Government) on other clusters and nodes?" and "What government's actions are the most influential?" When filling the matrixes for the network in the Figure 1, experts should answer the question "What of two compared nodes (clusters) the analyzed node (cluster) influence more and how much more?" As result we had got pair comparison matrixes, like the following: 


\section{O. Andreichicova, A. Andreichicov / About some features of AHP/ANP applications}

\begin{tabular}{l|lllll|l}
$\begin{array}{l}\text { Comparing by the } \\
\text { cluster Banks }\end{array}$ & Banks & Producers & Population & Sc\&Tech & Macrofactors & \multirow{2}{*}{$\boldsymbol{w}$} \\
\hline Banks & 1 & 2 & 3 & 9 & 5 & 0,4574 \\
Producers & & 1 & 2 & 5 & 3 & 0,087 \\
$\begin{array}{l}\text { Population } \\
\text { Sc\&Tech }\end{array}$ & & & 1 & 3 & 2 & 0,1497 \\
Macrofactors & & & & 1 & $1 / 2$ & 0,2572 \\
& & & & & 1 & 0,0487
\end{tabular}

Limit priorities of the nodes are brought in Figure 1, where we can see zero values for the nodes of the cluster Government. As well we were interested in answering the question "What of the government's steps will have the most influence?", therefore we had turned up network and had passed to the inverted task that is shown in Figure 2.
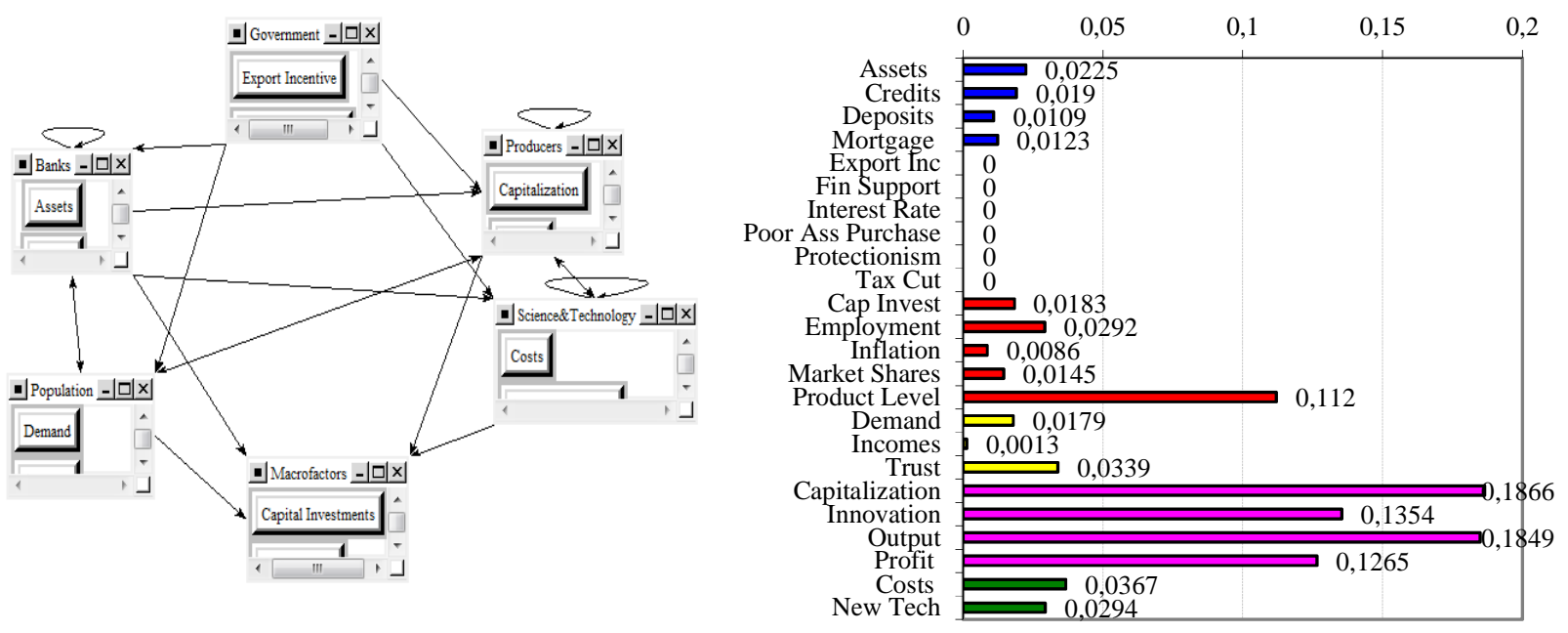

Figure 1. Network model for the problem of researching of financial crisis and limit priorities of the nodes.
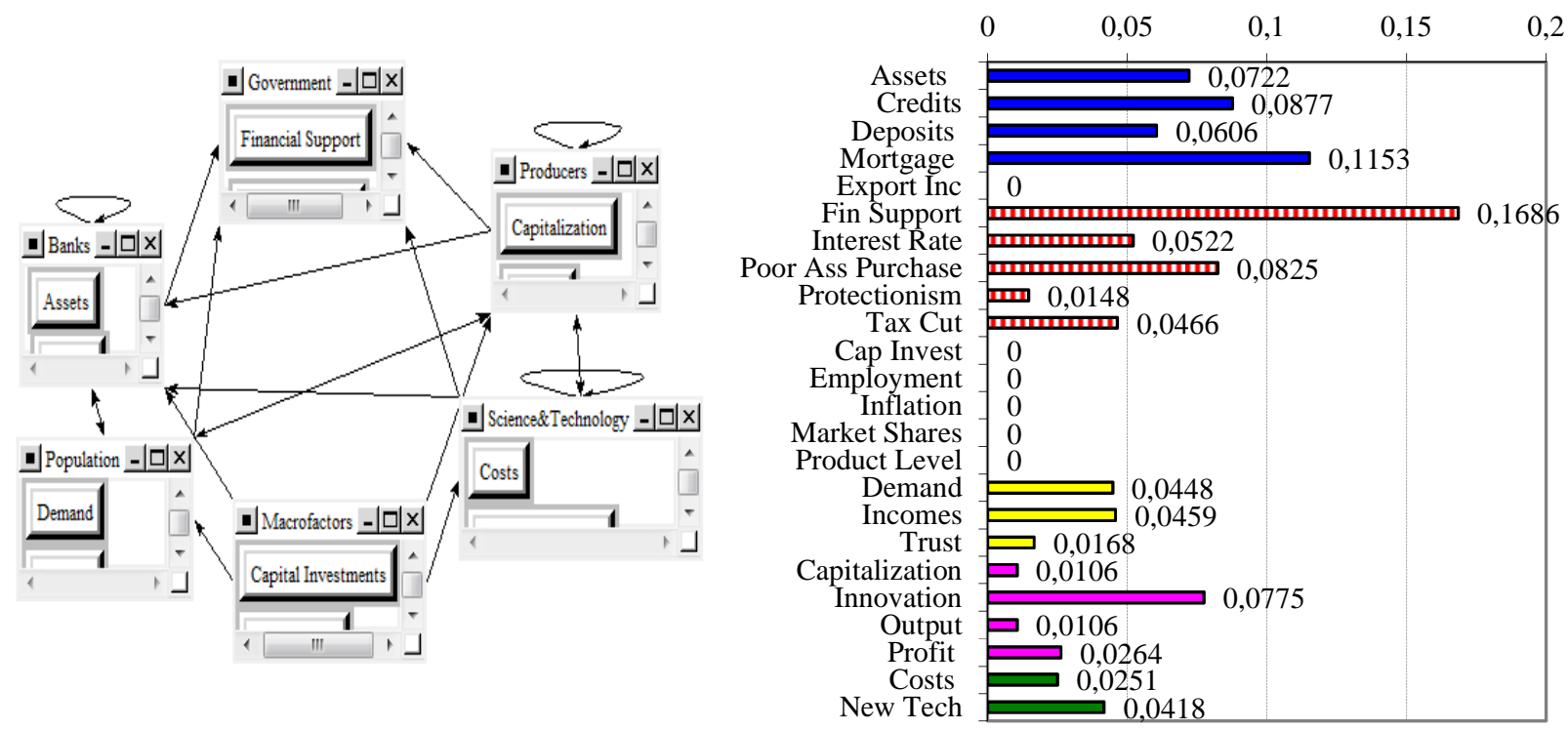

Figure 2. Inverted network for the problem of researching of financial crisis and limit priorities of the nodes. 
In Figure 2 we can see reverse direction of arrows. Note, this is not meant that influence direction has changed; we had to do that owing to use ANP software (Superdecisions sowtware, 2009) to fill pair comparison matrixes, which contain answers the question "What of two compared clusters (nodes) influence the analyzed cluster (node) more, and how much more?" Here is the example of a matrix

\begin{tabular}{l|lll|l}
$\begin{array}{l}\text { Comparing by } \\
\text { the cluster Banks }\end{array}$ & Banks & Government & Population & \multicolumn{1}{c}{$\boldsymbol{w}$} \\
\hline Banks & 1 & 2 & 3 & 0,4574 \\
$\begin{array}{l}\text { Government } \\
\text { Population }\end{array}$ & 1 & 2 & 0,087 \\
& & & 1 & 0,1497
\end{tabular}

Let's compare Figure 1 and Figure 2. In Figure 1 cluster Banks influence clusters Producers, Population, Sc\&Tech, Macrofactors and itself, i.e. Banks, therefore the first matrix has dimension of five and expresses influence of Banks other clusters. In turns, in Figure 1 we can see that cluster Banks is influenced by the clusters Government, Population and by itself, i.e. Banks. The last matrix shows, how these clusters influence cluster Banks. To do such comparison with use ANP software we had to change arrows' directions. We had done pair comparison matrixes for all remaining clusters and nodes likewise. Limit priorities of the nodes for the inverted task are brought in Figure 2, where one can see zero values for the nodes of cluster Macofactors, and non-zero values for the nodes of cluster Government. Thus it is possible to evaluate, what of the government's actions will have the most effect for researched model.

We would like to notice one important aspect in influences analysis that is connected with a sign of influence, which can be positive or negative. In general, one should not represent positive and negative influence in one network, as then the results will not be interpreted. In such cases one can construct two networks, which will show positive and negative influences separately, and then it is possible to generalize limit priorities of the same elements like BOCR technique.

\subsection{Experimental research of network structure}

Here we want to show the procedure of the network creation, which usually causes difficulties. The problem is to evaluate efficiency of expense items of state budget in Russian Federation. This urgent problem is complicated by non-transparency and political circumstances. We use the real data from open sources (http://www.minfin.ru/ru) about expense items of state budget for 2013 year. The simplest network for the problem is shown in Figure 3, which shows a sharing of budgetary funds. Main goal was to answer question "What part of budgetary funds is being accumulated in the elements (nodes, clusters)?"
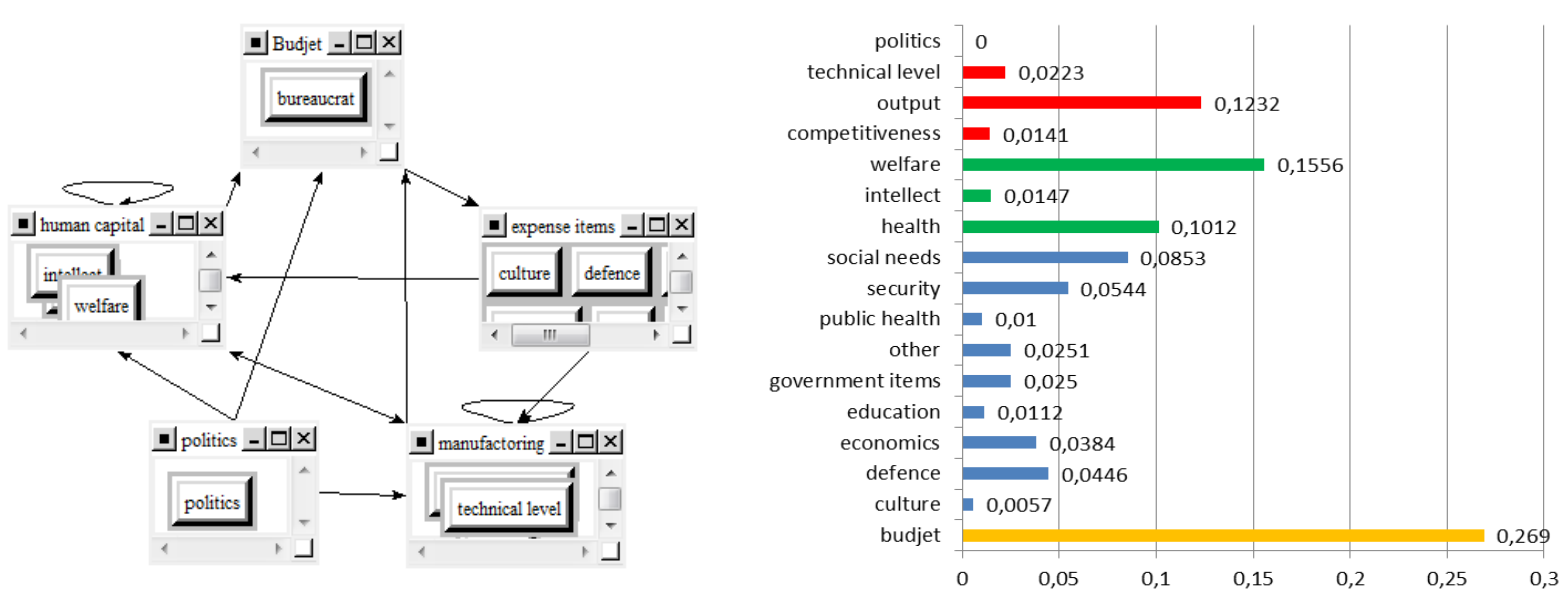

Figure 3. Network for the researching of efficiency of the budgetary funds' sharing of and limit priorities of nodes. 
We can see that $27 \%$ should return to Budget through the tax, which come from Manufacturing and Human capital clusters, and zero value for cluster-source Politics. Cluster Manufacturing contains three nodes - competitiveness, technical level and output, which has the greatest limit priority. Human capital is characterized by health, welfare and intellect, which has the least part of budget funds. Mutual influences of the elements one can see in supermatrix, which is brought in Appendix 1. The accordance of normalized priorities of elements of cluster Expense items with real data are shown in Figure 5. We can see that it is very good, but the real financing of manufacturing and human capital as well as return to budget poorly correspond with reality. We cannot have sufficient tax proceeds, when the most part of people has small incomes and a lot of manufacturers are very close to bankruptcy. The base of state budget consists of the tax proceeds from oil and gas sales as well as other minerals. In addition, Russia today has very high level of corruption and improper use of budgetary funds. To take into consideration these aspects we have added into network one cluster Bureaucracy, containing a single node. Bureaucracy is intermediate between Budget and real recipients of budget funds. Most of them have conflict of interests, when making decisions about the financing. Feedback between Expense items and Bureaucracy simulate corruption scheme named backoff (otkat in Russian). The model with this change and the limit priorities for its nodes are shown in Figure 4.
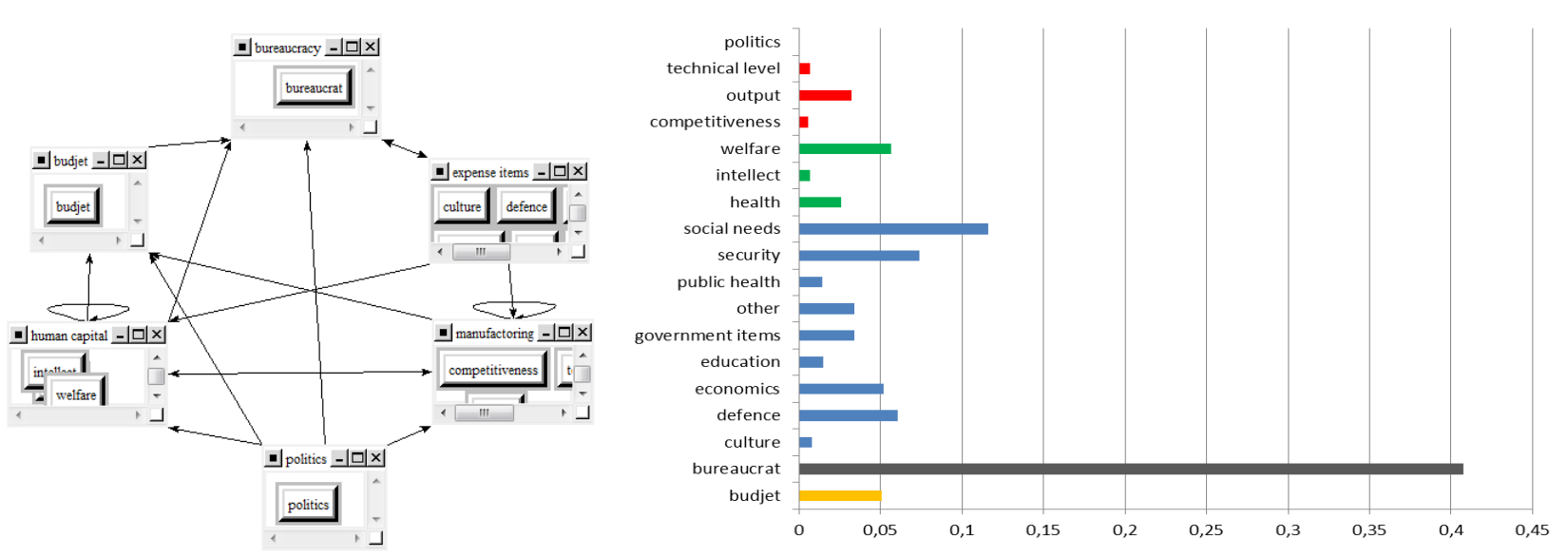

Figure 4. Changed network and limit priorities of its nodes.

We can see that the backoff exceeds $40 \%$ while the return to budget has dropped up to $5 \%$. Impact to Manufacturing and Human capital is appreciably reduced too. The comparison of limit priorities of the clusters is shown in Figure 5 that demonstrates reallocation of budgetary funds for benefit of bureaucracy and increasing of expense items, which are not connected with manufacturing and human capital.

This example illustrates the research procedure that can take place in the development of ANP application. Step-by-step complication of the network model enables to understand a difficult problem and to obtain the results, explaining reality. 

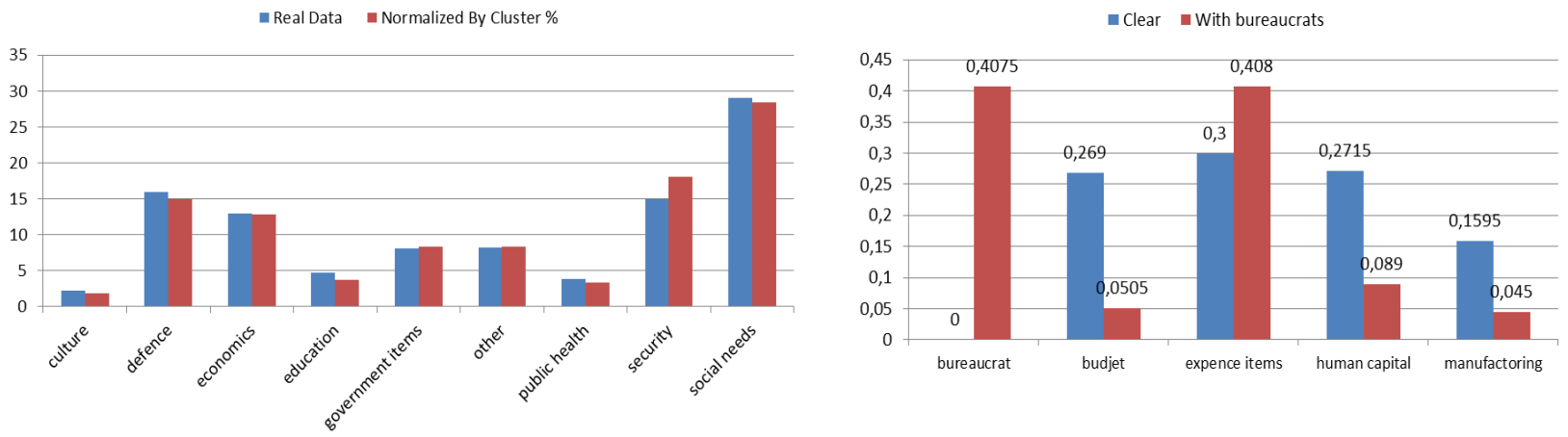

Figure 5. The comparison normalized limit priorities of expense items with real data (at the left) and comparison of limit priorities of clusters for two models (at the right).

\section{Conclusion}

This paper is an attempt to review main opportunities that AHP/ANP gives to researchers. In the teaching and consulting on AHP/ANP applications the most important and difficult steps are connected with the problem statement. Besides decision-making problems ANP can be used as the simulating tool that enables to research significant relations and influences in complex systems.

\section{REFERENCES}

Andreichicov A.V., Andreichicova O.N. (1999) Intelligent software based on AHP. Proceedings of the Fifth International Symposium on the Analytic Hierarchy Process (ISAHP'99), August 12-14, 1999, Kobe, Japan, p. 393-398.

Andreichicov A.V., Andreichicova O.N. (2003) The Analysis of the Technical Systems' Evolution. Proceedings of the 7th International Symposium on the Analytic Hierarchy Process (ISAHP'2003), August 7-9, 2003, Bali, Indonesia, p. 121-126.

Andreichicova O.N., Andreichicov A.V. (2009) Analytic Network Process as Qualitative Simulating Tool: Researching of Financial Crisis. Proceedings of $10^{\text {th }}$ International Symposium on the Analytic Hierarchy/Network Process Multi-criteria Decision Making (ISAHP'2009), July 29 - August 1 2009, University of Pittsburgh, Pittsburgh, Pennsylvania, USA, www.isahp.org

Andreichicova O.N., Radyshevskaya T.N. (2009) An application of the Analytic Network Process to researching oral health. International Journal of the Analytic Hierarchy Process, vol. 1, issue 1, 2009, pp. 45-60, http://ijahp.org.

Saaty, T.L. (1980) The Analytic Hierarchy Process. McGraw-Hill, New York NY.

Saaty, T.L. (1994) Fundamentals of Decision Making and Priority Theory with the Analytic Hierarchy Process. Pittsburg, PA: RWS Publications.

Saaty, T.L., Vargas L.G. (1994) Decision Making in Economic, Political, Social and Technological Environments with the Analytic Hierarchy Process. Pittsburg, PA: RWS Publications.

Saaty, T.L. (1999) Decision Making for Leaders: The Analytic Hierarchy Process for Decisions in a Complex World. Pittsburg, PA: RWS Publications. 
Saaty, T.L. (2001) Decision Making with Dependence and Feedback: The Analytic Network Process. Pittsburgh, PA: RWS Publications.

Saaty, T.L. (2005) Theory and Applications of the Analytic network Process: Decision Making with Benefits, Opportunities, Costs, and Risks. Pittsburg, PA: RWS Publications.

Saaty T.L., Ozdemir M.S. (2005) The Encyclicon: A Dictionary of Decisions with Dependence and Feedback Based on the Analytic Network Process. Pittsburgh, PA: RWS Publications.

Saaty T.L., Cillo B. (2008) The Encyclicon: A Dictionary of Complex Decisions Using the Analytic Network Process. Pittsburgh, PA: RWS Publications.

SuperDecisions software (2009) Software for the ANP, downloaded from the website http://www.superdecisions.com. 

Appemdix 1. Weighted supermatrix for Russian state budget problem.

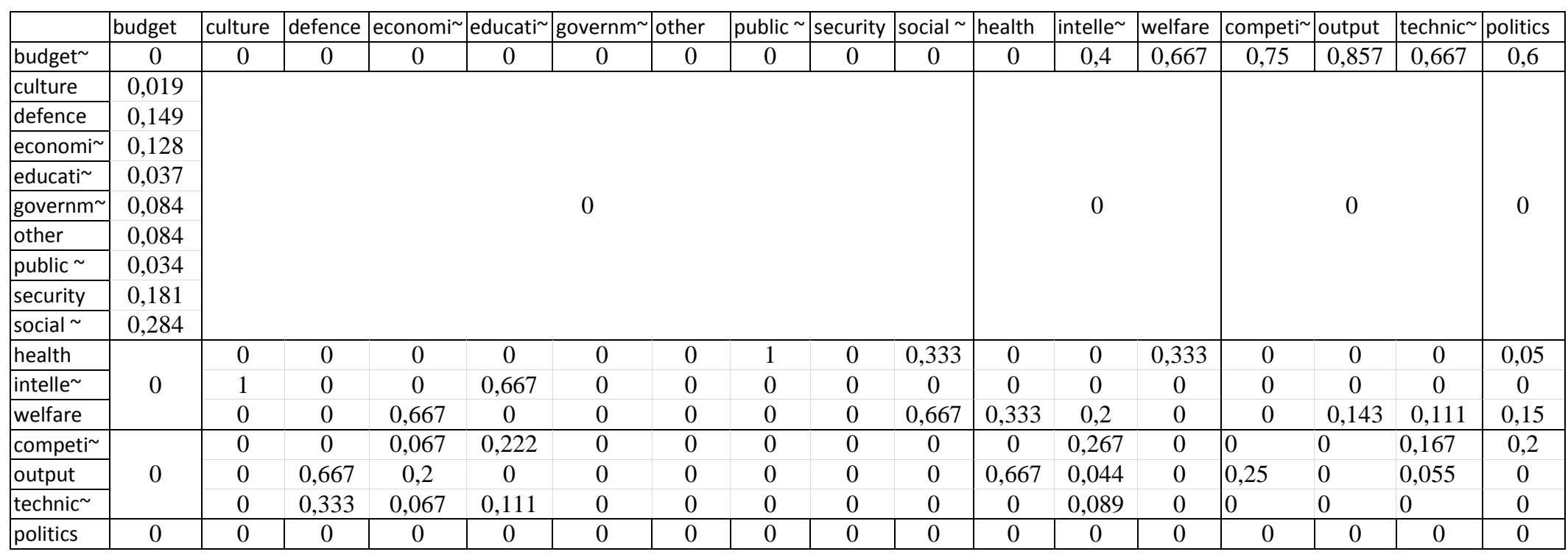

